\title{
Manganese Superoxide Dismutase Therapy in a Murine Hepatitis-Associated Injury
}

\author{
Yan Li, Nathaniel P. Reuter, Xuanshe Li, Robert Calvin Grier Martin* \\ Division of Surgical Oncology, Department of Surgery, University of Louisville School of Medicine, Louisville, USA. \\ Email: ${ }^{*}$ rcmart03@gwise.louisville.edu
}

Received June 28 ${ }^{\text {th }}, 2011$; revised August $23^{\text {rd }} 2011$, accepted May $25^{\text {th }}, 2011$.

\begin{abstract}
We aim to test the hypothesis that Con A-induced hepatitis and cell death can be prevented by the administration of the MnSOD mimetic MnTBAP. Male C57 mice were divided into 3 groups, 1) pretreated with MnTBAP (30 $\mathrm{mg} / \mathrm{kg})$ for 2 days and then Concanavalin A (Con A) (15 mg/kg);2) pretreated with saline for 2 days and then Con A (15 mg/kg); 3) was the control treated with saline for 3 days. Extensive hepatic necrosis, with a significant increase in apoptosis, lipid peroxidation and decreased MnSOD enzymatic activity was found in the hepatic tissue of Con A-treated mice with significantly attenuation of all factors by pretreatment with MnTBAP. MnTBAP protected hepatocytes from Con A-induced hepatic injury with less degree of liver inflammation-ConA $+\operatorname{MnTBAP}(2.1 \pm 0.4) v s$. Con A $(2.6 \pm 0.3)$-and significantly less cell death $(1.2 \pm 0.3$ vs. $2.7 \pm 0.4, p=0.03)$. MnSOD supplementation attenuated the oxidative-induced stress effects of Con A-induced injury and the protective effects of MnSOD supplementation against Con A-induced hepatitis could be through its anti-oxidative properties. Further evaluation of MnSOD manipulation could have the potential to prevent ongoing hepatic injury in hepatitis.
\end{abstract}

Keywords: Carcinogenesis, Hepatocellular Carcinoma, Chemoprevention, MnTBAP

\section{Introduction}

Hepatitis is a growing problem in North America and worldwide due to the hepatitis $\mathrm{B}$ and $\mathrm{C}$ viruses and ethanol abuse. The hepatitis B virus has a worldwide incidence of 2 billion people infected and 500 million carriers $[1,2]$. Additionally 1 million people die from hepatitis $\mathrm{B}$ infection annually through chronic hepatitis, cirrhosis, and hepatocellular carcinoma (HCC) [2]. Hepatitis C is also increasing in incidence with 170 million people infected worldwide and a prevalence of $2 \%$ in North America and more than $10 \%$ in portions of Central Africa and Egypt [3]. Ethanol also increases the neoplastic potential of the hepatitis $\mathrm{C}$ virus [4]. Regardless of the etiological agent, malignant transformation of $\mathrm{HCC}$ is known to occur through increased liver-cell turnover, induced by chronic injury and subsequent regeneration, in a context of inflammation and oxidative DNA damage [5].

Oxidative stress plays an integral role in progressive parenchymal liver injury associated with viral hepatitis, alcoholic liver disease, and non-alcoholic steatohepatitis [6-9]. The imbalance between reactive oxygen species (ROS) production and their elimination causes damage to cellular macromolecules in gingival fibroblasts. ROS are capable of oxidizing lipids, proteins and DNA that lead to the formation of oxidized products such as lipid hydroperoxide (LPO), protein carbonyls and 8-hydroxyguanosine [10]. It has been shown that the major LPO trans-4-hydroxyl-2-nonenal reacts with the DNA bases to produce modified DNA resulting in hepatic carcinogenesis [11]. To minimize the effect of ROS and free radicals, cells express enzymes such as superoxide dismutases, glutathione peroxidase, and catalase, which are pivotal in intracellular antioxidant defense in humans. A few antioxidants have been used to prevent hepatic oxidative damage both in vivo and in vitro with varying degrees of success [12].

Manganese superoxide dismutase (MnSOD) is the mitochondrial form of superoxide dismutase and catalyses superoxide anions to oxygen and hydrogen peroxide to protect cells against toxic effects of oxygen metabolism. It has been reported that MnSOD is a powerful antioxidant that can prevent carcinogenetic transformation [13]. Previously, we have demonstrated that administration of Mn (III) tetrakis [4-benzoic acid] porphyrin (MnTBAP), a MnSOD nonpeptide mimic, inhibited development of gastroesophageal reflux-induced Barrett's esophagus and 
esophageal adenocarcinoma, through the reduction of oxidative stress and increased activity of MnSOD [14]. However, the role MnSOD plays in the protection against hepatic injury is largely unknown.

Concanavalin A (Con A) is a lectin protein originally extracted from the jack bean [15]. During the last decade, a model of liver injury by Con A has been widely described and characterized. Liver injury in this model occurs following the production of lymphokines and monokines such as tumor necrosis factor alpha (TNF $\alpha)$, interferon gamma (INF $\gamma$ ), interleukin-6 (IL-6), and IL-1 [15-18]. In addition to the immune-mediated liver damage, reactive oxygen species (ROS) also play a role in Con A-induced hepatitis probably secondary to immune-mediated liver damage. Con A has also been shown to induce oxidative stress in addition to T-cell inflammatory infiltration [19]. Scavenging of reactive oxygen species by antioxidants prevents may be a new therapeutic target in this experimental model [20]. In the present study, we examined the hepatic damage by oxidative stress involved in the pathogenesis of Con A-induced hepatitis in mice. We tested the hypothesis that Con A-induced hepatitis can be prevented by the administration of the MnSOD supplementation.

\section{Methods}

\subsection{Animals and Treatment}

Male 25 - 30 g C57 mice (Jackson labs, Bar Harbor, ME) were housed three per cage, given commercial chow and tap water, and maintained on a 12-hour light/dark cycle. They were allowed to acclimate for two weeks prior to treatments. Animals were divided into three groups. The normal control group was treated with intraperitoneal (i.p.) saline daily for 3 days $(n=5)$. The Con A hepatic injury group was treated with saline (i.p.) for 3 days and then treated with Con A (i.v.) at $30 \mathrm{mg} / \mathrm{kg}(\mathrm{n}=15)$. The MnTBAP pretreated group was treated with MnTBAP (i.p.) at $10 \mathrm{mg} / \mathrm{kg}$ for 3 days and then treated with Con A (i.v.) at $30 \mathrm{mg} / \mathrm{kg}(\mathrm{n}=15)$. Twelve hours after the administration of $\mathrm{Con} \mathrm{A}$, the mice were euthanized by $\mathrm{CO}_{2}$ asphyxiation and the hepatic tissue was harvested for the measurements of histology, alanine aminotransferase (ALT), apoptosis, 8-hydroxy-deoxyguanosine (8-OH-dG), lipid peroxidation, and MnSOD expression and enzymatic activity. This study was approved by the Institutional Animal Care and Use Committee at the University of Louisville.

\subsection{ALT Activity}

Alanine aminotransferase (ALT) enzymatic activity of serum samples was determined using an ALT (GPT) Reagent kit according to the instructions provided
(Thermo Electron Corporation, Waltham, MA).

\subsection{Histopathology}

Samples of hepatic tissue from each mouse were fixed in $10 \%$ buffered formalin for 24 hours and transferred into $80 \%$ ethanol. The formalin-fixed tissue was embedded in paraffin. Five $\mu \mathrm{m}$ sections were mounted onto glass slides and stained with hematoxylin and eosin for histopathologic analysis. Histopathology changes including pericentral and lobular inflammation, and centrilobular cell death were graded on a severity scale from 0 to $3(0=$ no lesion, $1=$ mild, $2=$ moderate, $3=$ severe $)$.

\subsection{TdT Labeling (TUNEL) Assay}

ApopTag ${ }^{\circledR}$ in-situ apoptosis detection kit was used to detect the apoptotic cells according to the product instructions (Intergen Company, Purchase, NY). Five- $\mu \mathrm{m}$ thick sections were cut from the paraffin blocks. After deparaffinization and rehydration, endogenous peroxidase was blocked with $\mathrm{H}_{2} \mathrm{O}_{2}$ in methanol for 20 minutes. The sections underwent proteinase $\mathrm{K}$ digestion for 15 minutes. DNA fragments were tailed using digoxigenin-dUTP along with anti-digoxigenin antibody conjugation with horseradish peroxidase (HRP) along with the substrate $\left(\mathrm{DAB}-\mathrm{H}_{2} \mathrm{O}_{2}\right)$ to develop a brown color. An apoptotic index (the number of TUNEL positive epithelial nuclei/the number of total epithelial nuclei) was calculated.

\subsection{Imunoflurescent and Immunohistochemical Assays}

Immunofluorescent assay was performed on the frozen section. The slides were dried and blocked with $10 \%$ serum in PBS-T. After washing, CD4, IFN- $\gamma$ and IL-17 was stained by incubation with monoclonal antibodies (anti-CD4 antibody; anti-IFN- $\gamma$ antibody; anti-IL-17A antibody) labeled with fluorescein isothiocyanate (FITC). A negative control was included in each run. For visualization of CD4, IL-17A and IFN- $\gamma$, the signal of FITC was examined under fluorescent microscope at the oil objective $100 \times$ magnification.

Immunohistochemical staining was carried out on the paraffin-embedded material using the DAKO EnVision ${ }^{\mathrm{TM}}$ + System Kit (DAKO Corporation Carpinteria, CA). In brief, the sections were deparaffinized and hydrated. The slides were washed with a TRIS-buffer, and peroxidase blocking was performed for 5 minutes. After rewashing, the polyclonal rabbit $\mathrm{Ab}-8-\mathrm{OH}-\mathrm{dG}$ was applied for 30 minutes. The slides were rinsed, and the specimens were incubated with labeled polymer for 30 minutes at room temperature. The substrate-chromogen solution (diaminobenzidine) was added as a visualization reagent. A negative control was included in each run. The digital 
images of 8-OH-dG staining was acquired with the microscope at $40 \times$ magnification using the Spot camera via the MetaMorph ${ }^{\circledR}$ Imaging System (Universal Imaging Corporation., Downingtown, PA) and stored as JPG data files (the resolutions were fixed as 200 pixels/inch). The procedure for the computer image analysis was performed, and the acquired color images from the immunohistochemical staining were defined a standard threshold according to the software specification. The computer program then quantified the threshold area represented by color images. 8-OH-dG levels are defined by the percentages of threshold area in acquired color images.

\subsection{Lipid Peroxidation Assay}

Lipid peroxidation is quantified by an OXItek TBARS Assay kit (ZeptoMetrix Corporation, Buffalo, NY) measuring the malondialdehyde (MDA) concentrations as described in the provided instruction (Thiobarbituric acid-reactive substance assay). Briefly, the tissue homogenate is processed for thiobarbituric acid reaction following the procedure described. The reaction mixture is covered and incubated at $95^{\circ} \mathrm{C}$ for $60 \mathrm{~min}$ and then cooled to room temperature in an ice bath for $10 \mathrm{~min}$. The samples were centrifuged at $3000 \mathrm{rpm}$ for $15 \mathrm{~min}$, and the absorbance is obtained with a microplate reader reading at $532 \mathrm{~nm}$.

\subsection{SOD Enzymatic Activity Assay}

SOD enzymatic activity was determined by a SOD assay kit-WST (Dojindo Molecular Technologies, INC.) as previously described [22]. Briefly, the highly water-soluble tetrazolium salt WST-1 [2-(4-iodophenyl)-3-(4-nitrophenyl)-5-(2,4-disulfo-phenyl)-2H-tetrazolium, monosodium salt] produces a water-soluble formazan dye on reduction with a superoxide anion. Samples were tested and a standard curve ranging from 0.156 to 20 units $/ \mathrm{ml}$ was prepared. The colorimetric assay is done measuring formazan produced by the reaction between WST-1 and superoxide anion $\left(\mathrm{O}_{2}\right)$. The rate of the reduction with $\mathrm{O}_{2}$ was linearly related to the xanthine oxidase activity and is inhibited by SOD. The absorbance was obtained with a microplate reader reading at $450 \mathrm{~nm}$. MnSOD activity is determined by adding $1 \mathrm{mmol} / \mathrm{L} \mathrm{KCN}$ to samples to block $\mathrm{Cu} / \mathrm{ZnSOD}$ activity completely and then subtracting the $\mathrm{Cu} / \mathrm{ZnSOD}$ activity from the total SOD activity.

\subsection{MnSOD Protein Level Assay}

MnSOD protein levels in the hepatic tissue were determined by a Western blot analysis of MnSOD expression. In brief, total protein is isolated from fresh tissue samples by homogenization in ice-cold buffer containing 20 $\mathrm{mmol} / \mathrm{L}$ HEPES (pH 7.5), $1.5 \mathrm{mmol} / \mathrm{L} \mathrm{MgCl}_{2}, \mathrm{mmol} / \mathrm{L}$ DTT, $0.4 \mathrm{~mol} / \mathrm{L} \mathrm{NaCl}, 20 \%$ glycerol, $0.5 \mathrm{mmol} / \mathrm{L}$ phenylmethylsulfonyl fluoride, and $0.5 \mathrm{mmol} / \mathrm{L}$ leupeptin at $4^{\circ} \mathrm{C}$. Insoluble cellular material is removed by microcentrifugation at $16,000 \times \mathrm{g}$ for $5 \mathrm{~min}$, and total protein is determined spectrophotometrically. The protein samples are separated via SDS-PAGE and subsequently transferred to the nitrocellulose membrane for Western blot.

\subsection{Statistical Analysis}

SPSS version 16.0 was used for data analysis. Continuous variables were compared using a $t$-test. Values were expressed as mean \pm standard deviation. A two-tailed $p$-value $<0.05$ was considered significant.

\section{Resutls}

\subsection{Protection of MnTBAP against Con A-Induced Liver Injury in Mice}

Histological analysis revealed that Con A administration resulted in pronounced hepatocyte damage with a multifocal distribution of damage in large areas of the liver, consistent with the increased levels of serum ALT activities. Extensive hepatic cell death and inflammatory infiltration was evident on H\&E staining in the Con A-treated mice and attenuated in the MnTBAP-pretreated mice, while the control mice had healthy appearing hepatic tissue with no inflammation. The representative histological changes and analysis were shown in Figure 1(a). The histologic scoring regarding the inflammation and cell death was shown in Table 1. The ALT level in serum was markedly increased ALT values at $172.8 \mathrm{U} / \mathrm{L}$ $(p<0.01$ compared to control) in Con A-treated mice. The ALT level in the MnTBAP treated group was significantly attenuated to $66.3 \mathrm{U} / \mathrm{L}$, although the level is still elevated compared to that in the control group (15.8 $\mathrm{U} / \mathrm{L}, p<0.05$ ) (Figure 1B). The apoptotic index, which was determined by counting positive TUNEL-staining hepatocytes in Con A-challenged liver tissue, significantly increased $(10.4 \%$ in the Con A group) in comparison to the controls $(0.3 \%$ in the control group, $p$ $<0.01$ ). In the MnTBAP-treated group, however, the apoptotic index was significantly attenuated compared to that in the Con A mice $(3.5 \%$ in the MnTBAP group versus $10.4 \%$ in the Con A group) (Figure 2).

\subsection{CD4+ T Cells and Cytokines in Con A-challenged Liver}

Con A-induced hepatocyte injury is associated with massive CD4+ $\mathrm{T}$ cell activation and infiltration into the liver parenchyma, leading to secretion of the proinflammatory cytokines. In this study, immunofluo- 


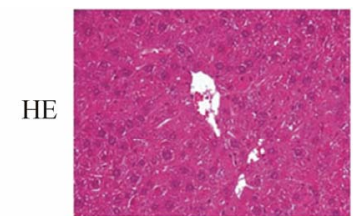

Control

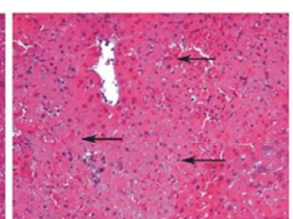

Con A

(a)

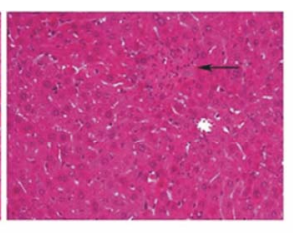

Con A + MnTBAP

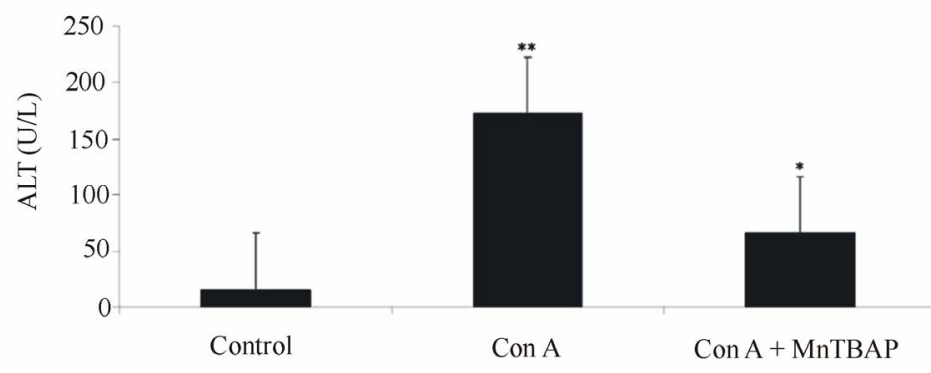

(b)

Figure 1. Effect of MnTBAP on Con A-induced hepatic injury. (a) Reprehensive histological changes in hepatic tissue with Con A challenge. Arrow: necrosis. Hematoxylin \& eosin staining (×200); (b) Effect of MnTBAP on ALT level in serum with Con A challenge. ${ }^{* *} p<0.05$ vs. controls; ${ }^{*} p<0.05$ vs. controls.

Table 1. Effect of MnTBAP on liver histology.

\begin{tabular}{cccc}
\hline & $\mathrm{n}$ & Inflammatory infiltration & Cell death \\
\hline Saline control & 6 & 0 & 0 \\
Con A & 12 & $2.6 \pm 0.3$ & $2.7 \pm 0.4$ \\
Con A + MnTBAP & 12 & $2.1 \pm 0.4$ & $1.2 \pm 0.3^{*}$ \\
\hline
\end{tabular}

Mice were sacrificed $12 \mathrm{~h}$ after Con A administration. Liver histology was evaluated on H\&E staining. Histopathology changes including pericentral and lobular inflammation and cell death were graded on a severity scale from 0 to $3(0=$ no lesion, $1=$ mild, $2=$ moderate, $3=$ severe $)$. Mean $\pm \mathrm{SD}, * \mathrm{P}<0.05$.

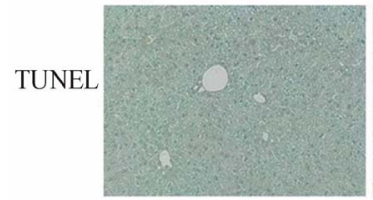

Control

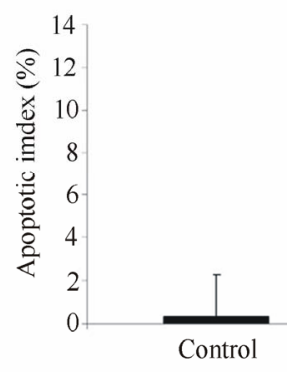

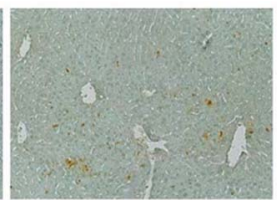

Con A

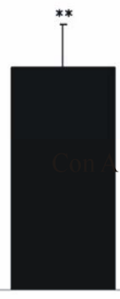

Con A

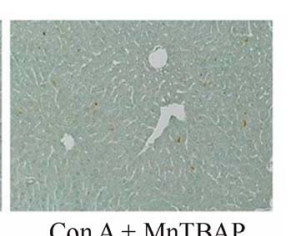

Con A + MnTBAP

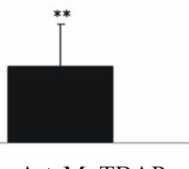

Figure 2. Effect of MnTBAP on Con A-induced apoptosis Representative apoptotic changes in hepatic tissue with Con A challenge. The positive TUNEL staining cells (brown dots) is distributed widely in hepatic tissue with Con A challenge, but not in MnTBAP pretreatment. ${ }^{* *} p<0.05$ vs. controls.

rescent detection revealed high CD4 positive staining into hepatic sinusoids twelve hours after Con A injection. To study the involvement of the proinflammatory cytokines, IL-17A and interferon- $\gamma$ were mearsured in the Con A-challenged hepatic tissue. Actually, IL-17, an effector cytokine, has proinflammatory properties [21] 
and acts on a broad range of cell types to induce the expression of other cytokines (TNF, IL-1 $\beta$, IL-6, GM-CSF, G-CSF) and chemokines (CXCL1, CXCL8, CXCL10) [22-24]. It has been demonstrated that IL-17A is largely expressed in CD4+ T cells. We used immunofluorescent assay to detect the production of IL-17A and found an increased level of IL-17A in Con A-challenged hepatic tissue. We also measured IFN- $\gamma$ in each sample and the result showed that Con A also incresed the early production of IFN- $\gamma$. However, pretreatment with MnTBAP did not affect the CD4+ T cells infiltration and these two proinflammatory cytokines levels in the Con A-challenged hepatic tissue. The fluorescent staining of CD4, IFN- $\gamma$ and IL-17A in Con A-challenged hepatic tissue are shown in Figure 3.

\subsection{The Effect of MnTBAP on Oxidative Biomarkers in Con A-challenged Liver}

The measurements regarding oxidative biomarkers were performed in Con A-challenged hepatic tissues, 8-OH-dG measurement for DNA oxidative damage and malondialdehyde (MDA) measurement for lipid peroxidation. The measurement of $8-\mathrm{OH}-\mathrm{dG}$ in the hepatic tissues was evaluated by immunohistochemical staining along with computer image analysis. The level of $8-\mathrm{OH}-\mathrm{dG}$ was significantly increased in the hepatic tissues of Con
A-challenged mice compared with the saline controls $(38.7 \pm 5.8$ vs. $18.6 \pm 5.2, p<0.01)$. However, the level of $8-\mathrm{OH}-\mathrm{dG}$ was significantly decreased when the Con A-challenged mice pretreated with MnTBAP (25.8 \pm 3.5 vs. $18.6 \pm 5.2$ saline controls). The TBARS results indicated that level of MDA in the hepatic tissues of Con A-challenged mice was considerably increased compared to saline controls. The level of MDA was the highest in the Con A group at $10.5 \pm 0.6 \mathrm{nmol} / \mathrm{ml}$ compared to the $3.2 \pm 0.9 \mathrm{nmol} / \mathrm{ml}$ in the control group $(p<0.01)$ However, treatment with MnTBAP also resulted in a significant decrease in the levels of lipid peroxidation products in the hepatic tissues of Con A-challenged mice. Pretreatment with MnTBAP effectively suppressed MDA level by Con A $(2.7 \pm 0.9 \mathrm{nmol} / \mathrm{ml})$ which was lower than the Con A group but not different from the control group $(p=0.3)$. The results of $8-\mathrm{OH}-\mathrm{dG}$ and TBARS are shown in Figure 4.

\subsection{The Effect of MnTBAP on MnSOD in Con A-challenged Liver}

The MnSOD protein expression and MnSOD enzymatic activity were determined in the hepatic tissues of each sample. The results indicated that the level of MnSOD expression decreased in the hepatic tissues 12 hours after Con A administration. Pretreatment with MnTBAP at
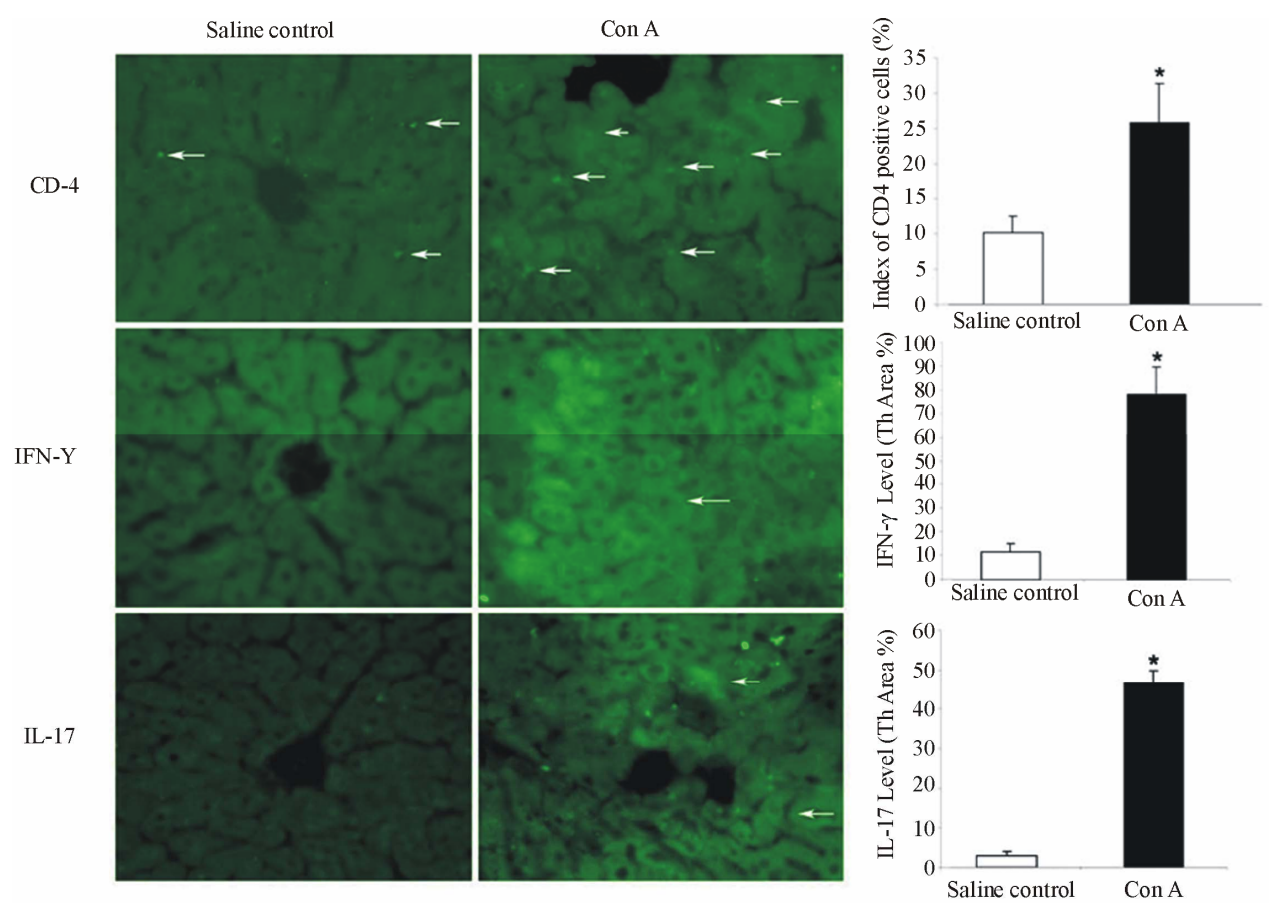

Figure 3. CD4+ cells, IFN- $y$ and IL-17A in hepatic tissue with Con A challenge. Top: FITC-immunofluorescent detection of CD4+ cells, arrow: CD4 positive cells; middle: FITC-immunofluorescent detection of IFN- $\gamma$, arrow: positive staining; bottom: FITC-immunofluorescent detection of IL-17A, arrow: positive staining. The level of positive staining was quantified computer image-analysis. The computer program quantified the threshold area represented by color images. ${ }^{*} p<0.05$ vs. controls. 


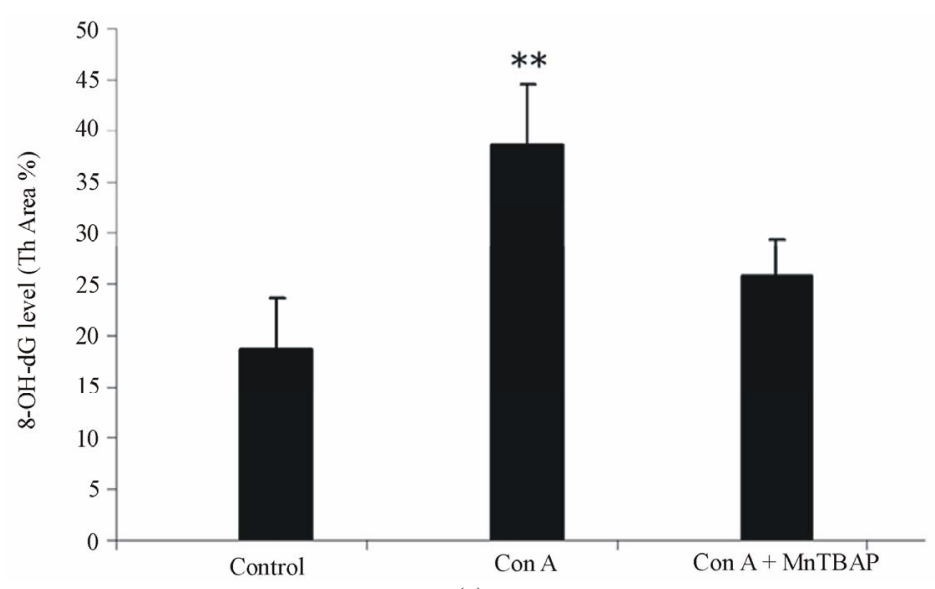

(a)

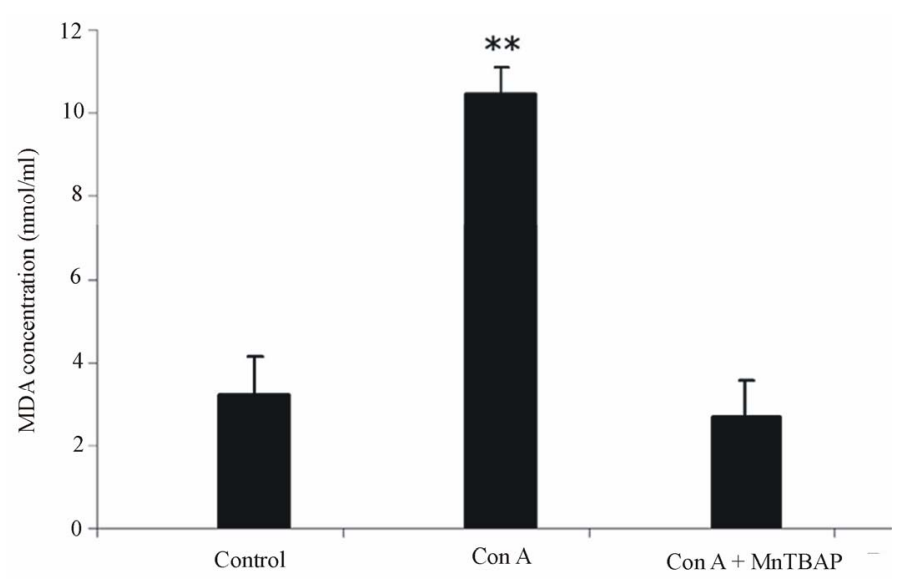

(b)

Figure 4. Effect of MnTBAP on 8-OH-dG and lipid peroxidation, The level of 8-OH-dG in hepatic tissue detected by immunohistochemistry using computer image-analysis. The computer program quantified the threshold area represented by color images; (b): the level of lipid peroxidation in hepatic tissue. Malondialdehyde (MDA) concentrations were measured representing the level of lipid peroxidation. ${ }^{* *} p<0.05$ vs. controls.

tenuated the decreased level of MnSOD in the Con A-insulted hepatic tissue. We further measured the MnSOD enzymatic activity; there was also a significant loss of total MnSOD activity observed in the hepatic tissues of Con A-challenged mice compared to that of control animals. MnSOD activity was highest in the control group (0.5\%), suppressed in the Con A group $(0.3 \%, p<$ 0.01 compared to control), and preserved in the MnTBAP-pretreated group $(0.4 \%, p=0.1$ compared to control). The loss of MnSOD in Con A-challenged hepatic tissues was ameliorated by MnTBAP pretreatment. The results of MnSOD expression and MnSOD enzymatic activities are shown in Figure 5.

\section{Discussion}

In this study, Con A-induced hepatitis is used to address the issues of whether alterations of MnSOD protein expression and enzymatic activity are involved in the pathogenesis of Con A-induced hepatitis in mice, and whether supplementmentation with MnTBAP, a MnSOD nonpeptidyl mimic, can attenuate the hepatic injury by Con A. Our results demonstrate that Con A-induced hepatic injury is associated not only with activation of $\mathrm{T}$ lymphocytes and related cytokines, but also with oxidative stress. The increased levels of $8-\mathrm{OH}-\mathrm{dG}$ and lipid peroxidation and loss of MnSOD were observed in the Con A-challenged hepatic tissues. Supplementation with MnTBAP attenuated the decreased MnSOD protein level and MnSOD enzymatic activity, and decreased the elevated levels of $8-\mathrm{OH}-\mathrm{dG}$ and MDA in Con A-challenged hepatic tissue. Pretreatment with a MnTBAP suppresses the increased ALT and cell death by Con A. The hepatic protective effect of MnTBAP is associated with the prevention of loss of MnSOD. However, pretreatment with MnTBAP did not affect CD4 T lymphocytes infiltration and the related proinflammatory 


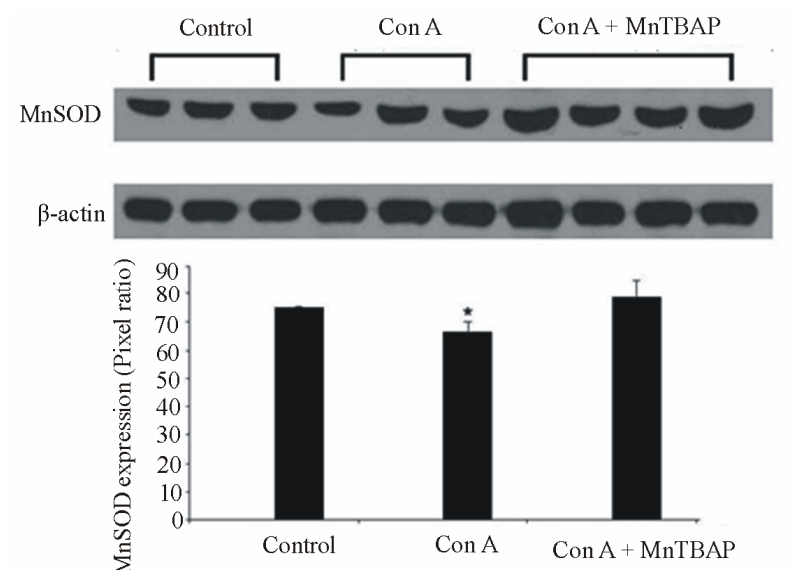

(a)

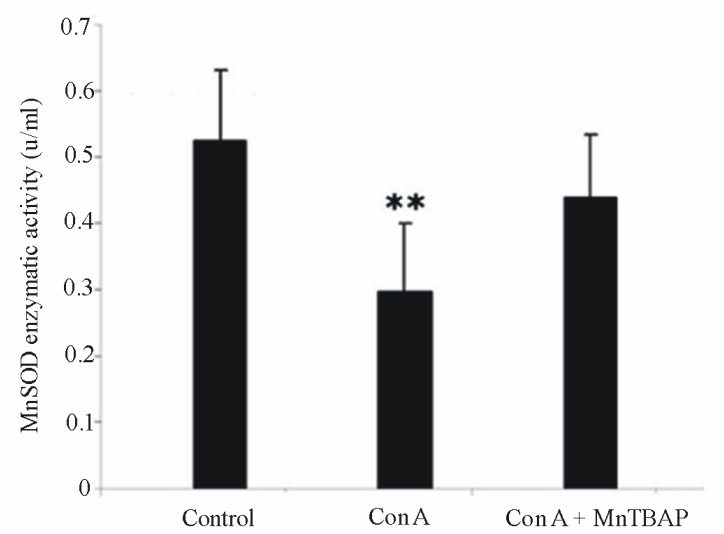

(b)

Figure 5. Effect of MnTBAP on MnSOD protein expression and enzymatic activity. (a) MnSOD level in total protein extracted from the hepatic tissues in mice with Con A challenge and MnTBAP pretreatment. (b) MnSOD enzymatic activity the hepatic tissues in mice with Con A challenge and MnTBAP pretreatment. ${ }^{* *} p<0.05$ vs. controls; ${ }^{*} p<0.05$ vs. controls.

cytokines levels of IL-17 and IFN- $\gamma$, thus suggesting that the protective effect of MnTBAP against Con A-induced hepatic injury could be from its antioxidant action, which is independent from the inhibition of inflammation.

Although Con A has been shown to be toxic to primary hepatocytes in vitro, Con A represents a useful animal model for investigating cytoprotective mechanisms against inflammatory liver injury because the in vivo hepatocyte death by Con A is independent of its chemical hepatotoxic insult. Activation of immune cells is necessary for Con A hepatotoxicity because of immunodeficiency and depletion of immune cells in animals shown to be resistant to hepatotoxic cell death following Con A injection [15,25-27]. In general, Con A-induced hepatic injury is assumed to occur by activated Kupffer cells secreting tumor necrosis factor (TNF), interleukin-12, and interleukin-18, and they then activate $\mathrm{T}$ cells including natural killer T cells. TNF and IFN- $\gamma$ are believed to be hepatotoxic and critical for Con A-hepatitis [28]. In the present study, there is an element of hepatitis and inflammatory injury evidenced by the increased ALT, necrosis and apoptosis in the Con A-administrated group compared to the control group. Numerous CD4-positive cells along with increased levels of IFN- $\gamma$ were found in the hepatic tissue subjected to Con A administration, which was in agreement with most Con A-hepatic injury studies [29-31]. It has been shown that IL-17 and IL-17RA signaling is critical for full development of hepatitis by Con A [32]. We further measured the IL-17A and found that IL-17A level was increased in Con A-challenged hepatic tissue. IL-17 is an emerging cytokine family that consists of six family members (termed IL-17A through IL-17F) and IL-17 genes show relatively restricted expression in $\mathrm{CD} 4+\mathrm{T}$ cells and are implicated in host defense [21]. All the results indicate that T-cell-mediated inflammatory liver injury occurs when hepatocytes are targeted by activated inflammatory cells and proinflammatory cytokines. However, the Con A-induced hepatitis was partially reversed by pretreatment with the MnSOD mimetic MnTBAP even though the CD4+ T cells' infiltration and the production of proinflammatory cytokines did not change at all. This finding confirms the lack of effects of MnTBAP on inhibiting inflammatory cytokines and more to the mechanistic effects of antioxidant effects.

Accumulating evidence indicates that oxidative stress involved in Con A-induced hepatitis is probably secondary to immune-mediated liver damage. Administration with antioxidants can attenuate Con A-induced hepatitis $[19,20]$. A recent study showed that the production of superoxide and ROS from the Con A-activated Kupffer cells plays a critical role in this hepatitis [33]. All these data support our current findings. In our study, decreased MnSOD protein expression and MnSOD enzymatic activity, as well as elevated levels of 8-OH-dG and MDA, were found in Con A-challenged hepatic tissue. Supplementation with MnTBAP may prevent hepatic injury, and this preventive effect is associated with the attenuation of loss of MnSOD and oxidative damages. Our results indicate that oxidative stress caused cell death contributes to, at least in part, Con A-induced hepatic injury. The levels of 8-OH-dG and MDA, but not the inflammatory parameters suppressed in the MnTBAP-pretreated animal, suggest a link between the MnTBAP-scavenging superoxide action and hepatic protection from oxidative-caused cell death. The possible mechanisms for ROS-caused cell death are the following. First, ROS released from activated Kupffer cells/macrophages and 
neutrophils can damage cellular macromolecules in hepatocytes, leading to necrosis [33,34]. Second, necrotic cell debris can lead to activation of proinflammatory cytokine signaling and amplification of the initial inflammatory response [35]. Last, inflammatory cytokine signaling can be further enhanced by ROS because a number of proinflammatory signaling proteins can be regulated in a redox-sensitive fashion [36].

T-cell-mediated inflammatory liver injury, in which hepatocytes are targeted by activated inflammatory cells, is related closely to the episode that happened in chronic hepatitis of virus (HVB and HVC), cirrhosis, and the increased incidence of HCC. The oxidative stressmediated destruction of hepatocytes during hepatic inflammatory injury is implicated in the progression of acute inflammatory liver injury to chronic inflammatory liver disease. Therefore, preservation of antioxidants in the challenged and compromised liver may have therapeutic applications against liver injury by chronic active hepatits, thereby preventing the fibrotic process and carcinogenetic transformation [37-39]. Frequently there is a latency period of several years between the onset of chronic viral hepatitis or cirrhosis and malignancy. This latency period provides an ideal opportunity for secondary prevention of primary hepatic malignancy and progression of hepatic disease. The MnSOD mimetic used in this experiment was Manganese III tetrak, an established chemopreventive therapy utilized in our lab in previous animal models [40]. In this current study, the hepatic protective effect could be from its scavenging superoxide action. In addition the effect of superoxide dismutase, MnTBAP has also shown a broad-spectrum ROS scavenge effect and prevents oxidative injury in a wide variety of cell lines and animals [41-44]. While MnTBAP is not readily available for oral administration to humans, this data highlights the importance of identifying an orally available compound that can combat oxidative stress in humans.

This study does have several limitations, the largest being its short-term nature. While oxidative stress is attenuated in the short term, we do not have any longer term data. A more realistic long-term hepatic injury model, such as chronic ethanol ingestion or carbon tetrachloride-induced liver fibrosis, would be advantageous. Another limitation is the mechanism study of oxidative stress by Con A. It is highly unlikely to perform an in vitro study regarding Con A-induced hepatocytes injury since this is an acute injury model. However, pretreatment with gadolinium chloride to block the Kupffer cells can help to clarify whether the oxidative damage is from Kupffer-cell-released superoxide. Further study regarding the injurious and protective mechanisms is needed.

\section{Conclusions}

In summary, this study provides groundwork regarding oxidative stress involved in Con A-induced hepatitis and the protective effect of MnTBAP. The next step is to continue the search for an orally available compound that would up regulate MnSOD enzymatic activity and attenuate oxidative stress in experimental hepatic injury models. Any orally available compound demonstrated to work in the acute setting will then be studied in a chronic setting (i.e., chronic ethanol ingestion) and eventually be tested for safety in a primate model.

\section{Acknowledgements}

Declaration of Interest: The project described was supported by Award Number R03CA137801 from the National Cancer Institute. The content is solely the responsibility of the authors and does not necessarily represent the official views of the National Cancer Institute or the National Institutes of Health.

\section{REFERENCES}

[1] D. Lavanchy, "Hepatitis B Virus Epidemiology, Disease Burden, Treatment, and Current and Emerging Prevention and Control Measures," Journal of Viral Hepatitis, Vol. 11, No. 2, 2004, pp. 97-107. doi:10.1046/j.1365-2893.2003.00487.x

[2] W. M. Lee, "Hepatitis B Virus Infection," The New England Journal of Medicine, Vol. 337, 1997, pp. 1733-1745. doi:10.1056/NEJM199712113372406

[3] A. Wasley and M. J. Alter, "Epidemiology of Hepatitis C: Geographic Differences and Temporal Trends," Seminars in Liver Disease, Vol. 20, 2000, pp. 1-16. doi:10.1055/s-2000-9506

[4] A. K. Singal and B. S. Anand, "Mechanisms of Synergy between Alcohol and Hepatitis C Virus," Journal of Clinical Gastroenterology, Vol. 41, No. 8, 2007, pp. 761-772. doi:10.1097/MCG.0b013e3180381584

[5] M. Levrero, "Viral Hepatitis and Liver Cancer: The Case of Hepatitis C," Oncogene, Vol. 25, 2006, pp. 3834-3847. doi:10.1038/sj.onc. 1209562

[6] S. Chitturi and G. C. Farrell, "Etiopathogenesis of Nonalcoholic Steatohepatitis," Seminars in Liver Disease, Vol. 21, No. 1, 2001, pp. 27-41. doi:10.1055/s-2001-12927

[7] M. Vidali, S. F. Stewart and E. Albano, "Interplay between Oxidative Stress and Immunity in the Progression of Alcohol-Mediated Liver Injury," Trends in Molecular Medicine, Vol. 14, No. 2, 2008, pp. 63-71. doi:10.1016/j.molmed.2007.12.005

[8] E. Albano, "Alcohol, Oxidative Stress and Free Radical Damage," Proceedings of the Nutrition Society, Vol. 65, No. 3, 2006, pp. 278-290. doi:10.1079/PNS2006496

[9] J. Choi and J. H. Ou, "Mechanisms of Liver Injury. III. Oxidative Stress in the Pathogenesis of Hepatitis C Vi- 
rus," American Journal of Physiology-Gastrointestinal and Liver Physiology, Vol. 290, No. 5, 2006, pp. G847-G851. doi:10.1152/ajpgi.00522.2005

[10] D. Hutter and J. J. Greene, "Influence of the Cellular Redox State on NF-kappaB-Regulated Gene Expression," Journal of Cellular Physiology, Vol. 183, No. 1, 2000, pp. 45-52. doi:10.1002/(SICI)1097-4652(200004)183:1<45::AID-JC P6>3.0.CO;2-P

[11] H. Bartsch and J. Nair, "Accumulation of Lipid Peroxidation-Derived DNA Lesions: Potential Lead Markers for Chemoprevention of Inflammation-Driven Malignancies," Mutation Research, Vol. 591, No. 1-2, 2005, pp. 34-44. doi:10.1016/j.mrfmmm.2005.04.013

[12] W. E. Stehbens, "Oxidative Stress, Toxic Hepatitis, and Antioxidants with Particular Emphasis on Zinc," Experimental and Molecular Pathology, Vol. 75, No. 3, 2003, pp. 265-276. doi:10.1016/S0014-4800(03)00097-2

[13] L. W. Oberley, "Mechanism of the Tumor Suppressive Effect of MnSOD Overexpression," Biomedicine and Pharmacotherapy, Vol. 59, No. 4, 2005, pp. 143-148. doi:10.1016/j.biopha.2005.03.006

[14] R. C. Martin, Q. Liu, J. M. Wo, M. B. Ray and Y. Li, "Chemoprevention of Carcinogenic Progression to Esophageal Adenocarcinoma by the Manganese Superoxide Dismutase Supplementation," Clinical Cancer Research, Vol. 13, 2007, pp. 5176-5182. doi:10.1158/1078-0432.CCR-07-1152

[15] G. Tiegs, J. Hentschel, and A. Wendel, "A T Cell-Dependent Experimental Liver Injury in Mice Inducible by Concanavalin A," The Journal of Clinical Investigation, Vol. 90, No. 1, 1992, pp. 196-203. doi:10.1172/JCI115836

[16] H. Mizuhara, M. Uno, N. Seki, M. Yamashita, M. Yamaoka, T. Ogawa, K. Kaneda, T. Fujii, H. Senoh and H. Fujiwara, "Critical Involvement of Interferon Gamma in the Pathogenesis of T-Cell Activation-Associated Hepatitis and Regulatory Mechanisms of Interleukin-6 for the Manifestations of Hepatitis," Hepatology, Vol. 23, 1996, pp. 1608-1615.

[17] F. Gantner, M. Leist, S. Jilg, P. G. Germann, M. A. Freudenberg and G. Tiegs, "Tumor Necrosis Factor-Induced Hepatic DNA Fragmentation as an Early Marker of T Cell-Dependent Liver Injury in Mice," Gastroenterology, Vol. 109, 1995, pp. 166-176. doi:10.1016/0016-5085(95)90282-1

[18] F. Gantner, M. Leist, A. W. Lohse, P. G. Germann and G. Tiegs, "Concanavalin A-Induced T-Cell-Mediated Hepatic Injury in Mice: The Role of Tumor Necrosis Factor," Hepatology, Vol. 21, 1995, pp. 190-198.

[19] R. Bruck, H. Aeed, E. Brazovsky, T. Noor and R. Hershkoviz, "Allicin, the Active Component of Garlic, Prevents Immune-Mediated, Concanavalin A-Induced Hepatic Injury in Mice," Liver International, Vol. 25, No. 3, 2005, pp. 613-621. doi:10.1111/j.1478-3231.2005.01050.x

[20] H. Shirin, H. Aeed, A. Alin, Z. Matas, M. Kirchner, E. Brazowski, I. Goldiner and R. Bruck, "Inhibition of Im-
mune-Mediated Concanavalin A-Induced Liver Damage by Free-Radical Scavengers," Digestive Diseases and Sciences, Vol. 55, No. 2, 2009, pp. 268-275. doi:10.1007/s10620-009-0732-5

[21] J. K. Kolls and A. Linden, "Interleukin-17 Family Members and Inflammation," Immunity, Vol. 21, No. 4, 2004, pp. 467-476. doi:10.1016/j.immuni.2004.08.018

[22] D. V. Jovanovic, J. A. Di Battista, J. Martel-Pelletier, F. C. Jolicoeur, Y. He, M. Zhang, F. Mineau and J. P. Pelletier, "IL-17 Stimulates the Production and Expression of Proinflammatory Cytokines, IL-Beta and TNFAlpha, by Human Macrophages," Journal of Immunology, Vol. 160, 1998, pp. 3513-3521.

[23] Z. Yao, W. C. Fanslow, M. F. Seldin, A. M. Rousseau, S. L. Painter, M. R. Comeau, J. I. Cohen and M. K. Spriggs, "Herpesvirus Saimiri Encodes a New Cytokine, IL-17, Which Binds to a Novel Cytokine Receptor," Immunity, Vol. 3, No. 6, 1995, pp. 811-821. doi:10.1016/1074-7613(95)90070-5

[24] H. Park, Z. Li, X. O. Yang, S. H. Chang, R. Nurieva, Y. H. Wang, Y. Wang, L. Hood, Z. Zhu, Q. Tian and C. Dong, "A Distinct Lineage of CD4 T Cells Regulates Tissue Inflammation by Producing Interleukin 17," $\mathrm{Na}$ ture Immunology, Vol. 6, 2005, pp. 1133-1141. doi:10.1038/ni1261

[25] J. Schumann, D. Wolf, A. Pahl, K. Brune, T. Papadopoulos, N. van Rooijen and G. Tiegs, "Importance of Kupffer Cells for T-Cell-Dependent Liver Injury in Mice," American Journal of Pathology, Vol. 157, No. 5, 2000, pp. 1671-1683. doi:10.1016/S0002-9440(10)64804-3

[26] C. S. Bonder, M. N. Ajuebor, L. D. Zbytnuik, P. Kubes and M. G. Swain, "Essential Role for Neutrophil Recruitment to the Liver in Concanavalin A-Induced Hepatitis," Journal of Immunology, Vol. 172, 2004, pp. 45-53.

[27] K. Takeda, Y. Hayakawa, L. Van Kaer, H. Matsuda, H. Yagita and K. Okumura, "Critical Contribution of Liver Natural Killer T Cells to a Murine Model of Hepatitis," Proceedings of the National Academy of Sciences of the United States of America, Vol. 97, No. 10, 2000, pp. 5498-5503. doi:10.1073/pnas.040566697

[28] G. Tiegs, "T cells, NKT Cells, and NK Cells in an Experimental Model of Autoimmune Hepatitis," In: M. E. Gershwin, J. M. Vierling and M. P. Manns, Eds., Liver Immunology, Hanley \& Belfus Inc; Philadelphia, 2003, pp. 171-183.

[29] G. Beldi, Y. Wu, Y. Banz, M. Nowak, L. Miller, K. Enjyoji, A. Haschemi, G. G. Yegutkin, D. Candinas, M. Exley and S. C. Robson, "Natural Killer T Cell Dysfunction in CD39-Null Mice Protects against Concanavalin A-Induced Hepatitis," Hepatology, Vol. 48, No. 3, 2008, pp. 841-852. doi:10.1002/hep.22401

[30] T. Kawamura, K. Takeda, H. Kaneda, H. Matsumoto, Y. Hayakawa, D. H. Raulet, Y. Ikarashi, M. Kronenberg, H. Yagita, K. Kinoshita, T. Abo, K. Okumura and M. J. Smyth, "NKG2A Inhibits Invariant NKT Cell Activation in Hepatic Injury," Journal of Immunology, Vol. 182, No. 1, 2009, pp. 250-258.

[31] W. Jiang, R. Sun, R. Zhou, H. Wei and Z. Tian, "TLR-9 
Activation Aggravates Concanavalin A-Induced Hepatitis via Promoting Accumulation and Activation of Liver CD4+ NKT Cells," Journal of Immunology, Vol. 182, No. 6, 2009, pp. 3768-3774. doi:10.4049/jimmunol.0800973

[32] T. Nagata, L. McKinley, J. J. Peschon, J. F. Alcorn, S. J. Aujla and J. K. Kolls, "Requirement of IL-17RA in Con A Induced Hepatitis and Negative Regulation of IL-17 Production in Mouse T Cells," Journal of Immunology, Vol. 181, No. 11, 2008, pp. 7473-7479.

[33] H. Nakashima, M. Kinoshita, M. Nakashima, Y. Habu, S. Shono, T. Uchida, N. Shinomiya and S. Seki, "Superoxide Produced by Kupffer Cells Is an Essential Effector in Concanavalin A-Induced Hepatitis in Mice," Hepatology, Vol. 48, No. 6, 2008, pp. 1979-1988. doi:10.1002/hep. 22561

[34] H. Ohshima, M. Tatemichi and T. Sawa, "Chemical Basis of Inflammation-Induced Carcinogenesis," Archives of Biochemistry and Biophysics, Vol. 417, No. 1, 2003, pp. 3-11. doi:10.1016/S0003-9861(03)00283-2

[35] M. Karin and F. R. Greten, "NF-kappaB: Linking Inflammation and Immunity to Cancer Development and Progression," Nature Reviews Immunology, Vol. 5, 2005, pp. 749-759. doi: $10.1038 /$ nri1703

[36] H. Kamata, S. Honda, S. Maeda, L. Chang, H. Hirata and M. Karin, "Reactive Oxygen Species Promote TNFalpha-Induced Death and Sustained JNK Activation by Inhibiting MAP Kinase Phosphatases," Cell, Vol. 120, No. 5, 2005, pp. 649-661. doi:10.1016/j.cell.2004.12.041

[37] S. Kawanishi, Y. Hiraku, S. Pinlaor and N. Ma, "Oxidative and Nitrative DNA Damage in Animals and Patients with Inflammatory Diseases in Relation to Inflammation-Related Carcinogenesis," The Journal of Biological Chemistry, Vol. 387, No. 4, 2006, pp. 365-372. doi:10.1515/BC.2006.049

[38] K. Koike, "Molecular Basis of Hepatitis C Virus- Associ- ated Hepatocarcinogenesis: Lessons from Animal Model Studies," Clinical Gastroenterology and Hepatology, Vol. 3, No. 2, 2005, pp. S132-S135. doi:10.1016/S1542-3565(05)00700-7

[39] X. W. Wang, S. P. Hussain, T. I. Huo, C. G. Wu, M. Forgues, L. J. Hofseth, C. Brechot and C. C. Harris, "Molecular Pathogenesis of Human Hepatocellular Carcinoma," Toxicology, Vols. 181-182, 2002, pp. 43-47. doi:10.1016/S0300-483X(02)00253-6

[40] R. C. Martin, Q. Liu, J. M. Wo, M. B. Ray and Y. Li, "Chemoprevention of Carcinogenic Progression to Esophageal Adenocarcinoma by the Manganese Superoxide Dismutase Supplementation," Clinical Cancer Research, Vol. 13, 2007, pp. 5176-5182. doi:10.1158/1078-0432.CCR-07-1152

[41] M. Patel and B. J. Day, "Metalloporphyrin Class of Therapeutic Catalytic Antioxidants," Trends in Pharmacological Sciences, Vol. 20, No. 9, 1999, pp. 359-364. doi:10.1016/S0165-6147(99)01336-X

[42] S. Cuzzocrea, B. Zingarelli, G. Costantino and A. P. Caputi, "Beneficial Effects of Mn(III)Tetrakis (4-benzoic acid) Porphyrin (MnTBAP), a Superoxide Dismutase Mimetic, in Carrageenan-Induced Pleurisy," Free Radical Biology \& Medicine, Vol. 26, No. 1-2, 1999, pp. 25-33. doi:10.1016/S0891-5849(98)00142-7

[43] A. G. Estevez, N. Spear, S. M. Manuel, R. Radi, C. E. Henderson, L. Barbeito and J. S. Beckman, "Nitric Oxide and Superoxide Contribute to Motor Neuron Apoptosis Induced by Trophic Factor Deprivation," The Journal of Neuroscience, Vol. 18, No. 3, 1998, pp. 923-931.

[44] B. J. Day, I. Fridovich and J. D. Crapo, "Manganic Porphyrins Possess Catalase Activity and Protect Endothelial Cells against Hydrogen Peroxide-Mediated Injury," Archives of Biochemistry and Biophysics, Vol. 347, No. 2, 1997, pp. 256-262. doi:10.1006/abbi.1997.0341 